\title{
Opportunity cost and COVID-19: A perspective from health economics
}

\author{
Mario J. Olivera*1,2 (1) \\ Received: 25 Jun 2020
}

Published: 29 Dec 2020

\begin{abstract}
The substantial increase in demand for medical care in intensive care units (ICUs) caused by the recent appearance of coronavirus disease 2019 (COVID-19) has placed severe pressure on hospital beds. Although countries have intensified efforts to contain or delay the spread of COVID-19, they must prepare to cope with the growing demand for critical care inpatient beds or risk being overwhelmed by the pandemic. The subject of this paper is the COVID-19 pandemic and the opportunity cost from the perspective of health economics using the supply and demand model of hospital bed days in ICUs. In this context, it has been seen that there is an excess demand for hospital beds that exceeds the supply of bed days provided by the health system, generating opportunity costs for patients who cannot be admitted to ICUs because beds are not available. Policymakers must take into account the notion of opportunity cost to ensure that scarce resources are used efficiently because patients with and without COVID-19 will be competing for the same ICU resources.
\end{abstract}

Keywords: COVID-19, Intensive care units, Hospital bed capacity, Health services needs and demand, Economics medical, Costs and cost analysis

Conflicts of Interest: None declared

Funding: National Institute of Health

*This work has been published under CC BY-NC-SA 1.0 license.

Copyright $($ Iran University of Medical Sciences

Cite this article as: Olivera MJ. Opportunity cost and COVID-19: A perspective from health economics. Med J Islam Repub Iran. 2020 (29 Dec);34:177. https://doi.org/10.47176/mjiri.34.177

\section{Introduction}

\section{Editorial}

The recent emergence of coronavirus disease 2019 (COVID-19) on the world scene has drawn renewed attention to infectious diseases and highlights once again the challenges that emerging and reemerging infectious pathogens pose to global public health (1). Despite the reduction achieved in mortality caused by infectious diseases, such diseases remain a major threat globally (2). Some, such as malaria and Chagas disease, are endemic in many areas, in which they impose substantial economic burdens. Others fluctuate in intensity, cause outbreaks, such as measles, are preventable with vaccination and generate epidemics, such as Ebola or produce pandemics, such as COVID-19. The economic and health consequences are not the same for all countries, and they vary especially for low-income and middle-income countries (3-5).

In the current COVID-19 pandemic, terms that, despite first being typical of epidemiological language, have also become part of the common lexicon due to their continuous and almost daily use. In this sense, terms and epide- miological principles, such as basic reproducibility number Ro, are also used in common language in alternation with flattening the curve. In contrast, the health economics has failed to communicate and spread the concept of opportunity cost (6). This concept is of vital importance for the health economics since the notion of opportunity cost plays a crucial role in attempts to ensure that scarce resources are used efficiently $(7,8)$.

A worrying aspect is the limited discussion on the opportunity cost of the sectoral policies implemented and their impact in the field of health. When choosing an option among the alternatives, the opportunity cost is the cost of the alternative that we give up when we make a certain decision, including the benefits that we could have obtained from choosing the alternative option (9). In simple terms, the opportunity cost is the benefits we stop perceiving as a result of not selecting the next best option when we have limited resources (10). Opportunity cost is a key concept in economics and has been described as the basic relationship between scarcity and choice (10). This

\footnotetext{
Corresponding author: Dr Mario J. Olivera, molivera@ins.gov.co

1. Parasitology Team, National Institute of Health, Bogotá, DC, Colombia

2. Health Economics Program, Pontificia Universidad Javeriana, Bogotá, DC, Colombia
} 
work addresses the COVID-19 pandemic and its relationship with the notion of opportunity cost from the perspective of the health economy using the model of supply and demand for hospital bed days in intensive care units (ICUs).

Unfortunately, discussions of lockdown around the world present a false dichotomy between life and economy. Opportunity costs are not limited to monetary or financial costs: the actual cost of lost production, lost time, pleasure, or any other profit-making benefit should also be considered an opportunity cost $(6,7)$. The economic risks of pandemics are not symmetrical, and their effects are not distributed in the same way throughout the economy. Some sectors can even benefit, while others are seriously affected. One of the first sectors impacted by the COVID19 pandemic is the health system, both public and private. The substantial increase in demand for critical care limits the ability of this sector to solve routine health problems and worsens the problem. This sector must consider the opportunity cost in decision-making related to the allocation of scarce resources to improve the health of the population $(9,10)$.

The clinical spectrum of COVID-19 includes asymptomatic respiratory symptoms ranging from the common cold to severe pneumonia with respiratory distress syndrome, septic shock, coagulopathies, and multiorgan failure (11). Patients with severe symptoms require close monitoring in ICUs and mechanical ventilation support, which are key in the treatment of the disease (12). It is important to emphasize that in this scenario, the scarce resource is not hospital beds but bed days; it is not the mechanical fans but rather the ventilation time.

In this context, it has been seen that a temporary excess demand is generated for hospital beds that exceeds the supply of bed days by the health system. This increase in demand for bed days is due to the spread of infection, as hospitalized patients who are infected stay longer than

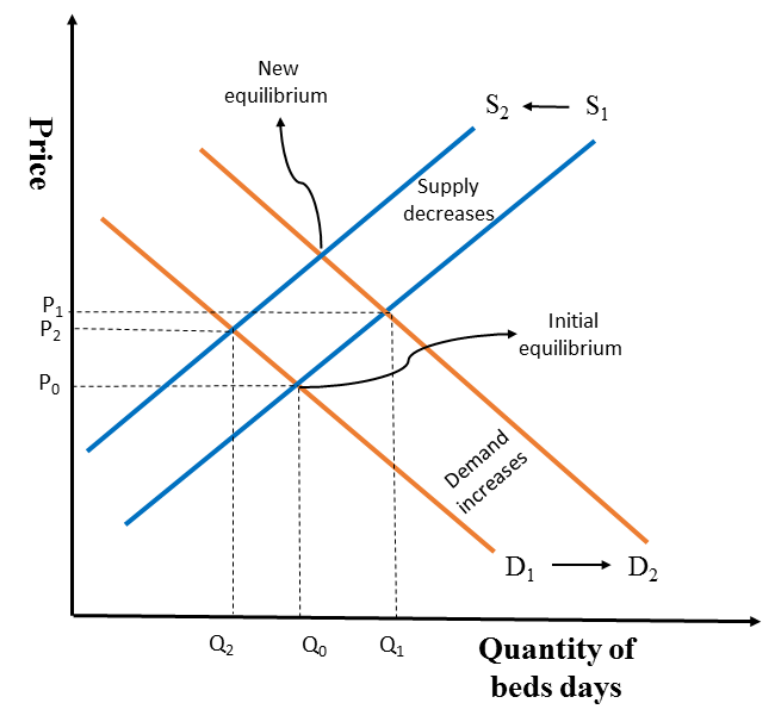

D: demand curves; S: supply curves; Q: quantity; P: price

Fig. 1. Demand and supply model for bed days they would without infection, shifting the demand curve to the right (see curve D2 in Fig. 1). Similarly, there may be a temporary decrease in the provision of bed days by the health system because beds can be isolated by hospital outbreaks. If this circumstance cannot be controlled, the supply decreases, shifting the supply curve to the left (see curve S2 in Fig. 1).

According to Arrow and the current theory of healthcare economics, perfect market conditions for medical services do not exist. Uncertainties, information asymmetries, and supply-side regulation are too great (13). Despite this, the approaches of the perfect competition model are very useful to express the notion of opportunity cost in the health sector (14). Market equilibrium in perfect competition is understood as the point where supply and demand are exactly the same (see points $\mathrm{P} 0$ and Q0 in Fig. 1). This equilibrium point is equal to the marginal opportunity costs and is a Pareto optimum; that is, at this point, no other allocation can achieve a better situation for some without others facing a worse situation. At this point, it is assumed that the market has produced a maximum result in relation to the Pareto partial order. Therefore, opportunity costs for other patients arise when they cannot be admitted to ICUs because beds are not available.

Policymakers must prepare for a substantial increase in critical care capacity $(15,16)$. Preparations should focus not only on infrastructure and supplies but also on personnel, including protection against nosocomial transmission and the promotion of mental well-being, taking into account the notion of opportunity cost since patients with and without COVID-19 will be competing for the same resources of ICU.

\section{Conflict of Interests}

The authors declare that they have no competing interests.

\section{References}

1. Cowling BJ, Leung GM. Epidemiological research priorities for public health control of the ongoing global novel coronavirus (2019nCoV) outbreak. Euro Surveill. 2020;25(6):2000110.

2. World Health organization. Global Health Observatory data. 2016. Available from: https:/www.who.int/gho/mortality_burden_disease/ en/

3. Olivera MJ, Buitrago G. Economic costs of Chagas disease in Colombia in 2017: A social perspective. Int J Infect Dis. 2020;91:196201

4. Centers for Disease Control and Prevention. Measles Cases and Outbreaks. 2020. Available from: https://www.cdc.gov/measles/casesoutbreaks.html

5. Wang C, Horby PW, Hayden FG, Gao GF. A novel coronavirus outbreak of global health concern. Lancet. 2020;395(10223):470-473.

6. Palmer S, Raftery J. Economic notes: opportunity cost. BMJ. 1999;318(7197):1551-1552.

7. Russell LB. Opportunity costs in modern medicine. Health Affairs.1992;11(2):162-169.

8. Drummond M. Sculpher K. Claxton G, Stoddart G. Torrance Methods for the economic evaluation of health care programmes (4th ed.), Oxford University Press, Oxford (2015).

9. Drummond MF, Sculpher MJ, Torrance GW, O'Brien BJ, Stoddart GL. Methods for the economic evaluation of health care programme. Third edition. Oxford: Oxford University Press; 2005.

10. Buchanan JM. Cost and choice: an inquiry in economic theory Chicago: University Chicago Press; 1969.

11. Wang Y, Wang Y, Chen Y, Qin Q. Unique Epidemiological and 
Clinical Features of the Emerging 2019 Novel Coronavirus Pneumonia (COVID-19) Implicate Special Control Measures. J Med Virol. 2020;92(6):568-576.

12. World Health Organization. Clinical management of severe acute respiratory infection when novel coronavirus $(\mathrm{nCoV})$ infection is suspected. 2020. Available from: https://who.int/publicationsdetail/clinical-management-of-severe-acute-respiratory-infectionwhen-novel-coronavirus-(ncov)-infection-is-suspected.

13. Arrow KJ. Uncertainty and the welfare economics of medical care. American Economic Review. 1963;53(5):941-973.

14. Lipsey R, Chrystal A. Economics. Oxford: Oxford University Press; 2015.

15. Global Preparedness Monitoring Board. A World at Risk: Annual Report on Global Preparedness for Health Emergencies. Geneva, Switzerland: World Health Organization; 2019.

16. Bennett B, Carney T. Planning for pandemics: lessons from the past decade. J Bioeth Inq. 2015;12:419-428. 